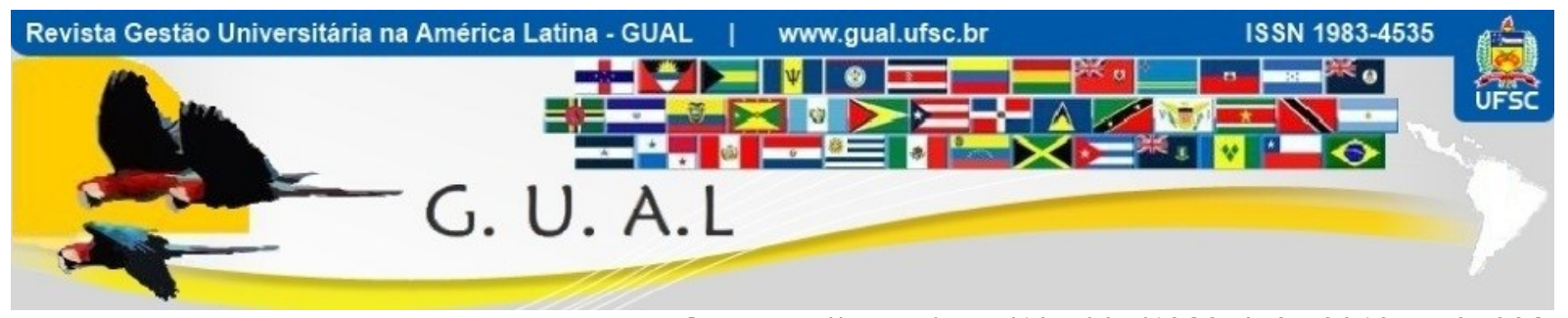

DOI: http://dx.doi.org/10.5007/1983-4535.2012v5n2p298

\title{
PERCEPÇÃO AMBIENTAL POR DIFERENTES GRUPOS SOCIOCULTURAIS DE INTERAÇÃO: O CASO DA UNIVERSIDADE FEDERAL DE SERGIPE, CAMPUS PROF. JOSÉ ALOÍSIO DE CAMPOS
}

\section{ENVIRONMENTAL PERCEPTION BY DIFFERENT SOCIOCULTURAL GROUPS OF INTERACTION: THE CASE OF UNIVERSIDADE FEDERAL DE SERGIPE, CAMPUS PROF. JOSÉ ALOÍSIO DE CAMPOS}

Priscila Christina Borges Dias Randow, Mestre Universidade Federal de Sergipe - UFS primundi@hotmail.com

Paulo Sérgio Maroti, PhD Universidade Federal de Sergipe - UFS paulo_teo@yahoo.com.br

Recebido em 07/fevereiro/2012

Aprovado em 17/julho/2012

Sistema de Avaliação: Double Blind Review

Esta obra está sob uma Licença Creative Commons Atribuição-Uso. 


\begin{abstract}
RESUMO
A pesquisa objetiva a caracterização do campus Prof. José Aloísio de Campos da Universidade Federal de Sergipe, a partir da percepção ambiental dos grupos de alunos, servidores técnico-administrativos, professores, pessoas do entorno e gestores. A metodologia baseia-se no modelo de Whyte (1977), com a coleta de dados representada por questionários e por entrevista não padronizada, associada ao teste gráfico do mapa mental, técnica utilizada para descobrir as imagens que as pessoas trazem quanto às relações espaciais e da paisagem, além de suas atitudes em relação à área em questão. A conjunção dos diferentes aspectos analisados mostra que apesar de os grupos perceberem mais marcadamente as áreas construídas do campus, estes possuem um grande laço afetivo com o espaço e o seu entorno, resultando na percepção dos impactos e na posterior escolha de cuidados, como a estruturação do espaço físico e a conservação e preservação do espaço natural, associadas às atividades principais de estudo e trabalho. Os resultados confirmam a importância deste estudo na elaboração de projetos de gestão universitária, respeitando as percepções dos grupos que atuam neste espaço.
\end{abstract}

Palavras-chave: Percepção ambiental. Paisagem. Gestão universitária.

\begin{abstract}
The research aims at the characterization of campus Prof. José Aloísio de Campos of the Universidade Federal de Sergipe, from the environment perception of groups of students, technical e administrative staff, teachers, the surrounding people and managers. The methodology is based on the model of Whyte (1977), with collection of data represented by questionnaires and interview not standardized, associated with the mind map test chart, a technique used to find the images that people carry in their heads, with regard to spatial relationships and landscape as well as their attitudes toward the area in question. The conjunction of different aspects examined show that despite more markedly groups realize the built-up areas of the campus, these have a great emotional bond with the space and its surroundings, resulting in the perception of impacts and subsequent choice of care, as the structuring of physical space and the conservation and preservation of its natural area, associated with the main activities of study and work. The results confirm the importance of this study in preparing projects of university management, respecting the perceptions of groups that operate in this space.
\end{abstract}

Keywords: Environmental perception. Landscape. University management. 


\section{INTRODUÇÃO}

O aumento da degradação do ambiente tem tornado explícita a necessidade de uma abordagem integrada na análise dos problemas ambientais, oferecendo subsídios ao planejamento do uso adequado do ambiente. Desse modo, a incorporação da percepção ambiental nos estudos da relação homem-ambiente contribui para uma utilização e gestão mais racional dos recursos ambientais e da paisagem, possibilitando uma relação harmônica dos conhecimentos locais do ponto de vista dos sujeitos, da coletividade ou da população em seu conjunto com a abordagem científica tradicional, enquanto instrumento educativo e agente de transformação (UNESCO, 1973).

As universidades brasileiras, vistas não somente como centros de formação de indivíduos, mas como pequenos centros urbanos consumidores de recursos naturais e geradores de resíduos, estão nos últimos anos passando por um processo de expansão significativo, o que transforma expressivamente sua paisagem.

Uma das universidades brasileiras em que se verifica essa expansão é a Universidade Federal de Sergipe (UFS), que contava com apenas dois espaços universitários (São Cristóvão e Aracaju) e que agora conta com cinco (Itabaiana, Laranjeiras e Lagarto). Todos esses campi possuem paisagens distintas, com ambientes importantes para conservação e proteção. Nessas paisagens, tanto os elementos naturais como os artificiais são elementos imprescindíveis para o estudo da percepção.

$\mathrm{Na}$ impossibilidade de investigar o sistema de percepção de todos os campi, esta pesquisa objetivou a caracterização do campus Prof. José Aloísio de Campos da Universidade Federal de Sergipe, a partir da percepção ambiental por diferentes grupos socioculturais de interação. Essa investigação justifica-se na perspectiva de obter informações que orientem a formulação de diretrizes para o planejamento da ocupação espacial e ambiental dessa unidade de paisagem urbana, incluindo estratégias para a conservação e educação ambiental, apoiadas no conhecimento das percepções dos indivíduos pertencentes a diferentes grupos socioculturais que exercem influências distintas sobre a área.

Alguns trabalhos, como Jesus (1993) e Santos et al. (2004), abordaram tal temática com a investigação da percepção de grupos socioculturais de interação, tendo como base o trabalho de Whyte (1977). Essa metodologia se baseia no emprego de mapas mentais, que são uma forma eficaz de armazenamento e comunicação de informações que estão no domínio cognitivo dos indivíduos. Com a análise dos mapas mentais, pode-se estudar as interações 
existentes entre o sujeito e o espaço em que vive, revelando os pontos mais representativos atribuídos ao ambiente.

\section{CONTRIBUIÇÕES TEÓRICAS}

\subsection{A percepção ambiental no estudo do espaço e da paisagem}

A percepção é um processo mental de interação do indivíduo com o meio ambiente que se dá através de mecanismos perceptivos captados pelos cinco sentidos (dos quais a visão é o que mais se destaca) e por processos cognitivos que incluem motivações, humores, necessidades, conhecimentos prévios, valores, julgamentos e expectativas (DEL RIO, 1996). Desse modo, cada pessoa tem uma percepção diferenciada para o mesmo objeto, que não pode ser considerada errada ou inadequada, mas sim condizente com o espaço vivido.

No estudo do espaço e da paisagem, a percepção é considerada importante porque serve como um instrumento de gestão para a sustentação de um plano de intervenções, a fim de proporem-se adequações e correções na paisagem estudada (FERNANDES et al., 2006). Portanto, compreender as interações entre o homem e a paisagem contribui para responder as perguntas de por que as paisagens são percebidas, como elas o são, o que elas significam para os indivíduos e os grupos e como elas contribuem para a sensação de bem-estar e qualidade de vida de todos (ZUBE; SELL; TAYLOR, 1982).

Segundo Del Rio (1996), ao se evitarem conflitos de percepção entre os sistemas cognitivos de vários grupos de atuação, como planejadores, empresários, grupos usuários e público em geral, a ação ambiental estará sendo direcionada para resultados mais satisfatórios e de maior qualidade.

\subsection{Gestão ambiental universitária}

As universidades são vistas pela maioria dos indivíduos somente como instituições pluridisciplinares responsáveis pela formação de quadros profissionais e de cultura. Mas, como outras instituições, as universidades são consumidoras de recursos naturais e geradoras de resíduos que impactam o ambiente.

Uma das mais eficientes formas de se reduzirem os impactos ambientais é com a implantação de um Sistema de Gestão Ambiental (SGA). Para Santos (2004), esse sistema só terá sucesso se ocorrer a integração entre planejamento, gerenciamento e política ambiental. Também é preciso a democratização dos processos de tomada de decisão, a ampliação da 
participação da sociedade civil na resolução dos problemas ambientais e a descentralização das atividades de monitoramento e fiscalização para garantir o direito de vigilância no cumprimento das ações, como afirmam Almeida et al. (2006) e Cunha e Coelho (2008).

Para estar atualizada com as novas discussões sobre gestão ambiental, a comunidade acadêmica deverá perceber os impactos ambientais originados, desenvolvendo a sensibilidade e os juízos corretos com respeito à realidade ambiental e propondo soluções que reduzam os impactos gerados. Isso promoverá uma melhor sustentabilidade no campus universitário, bem como uma melhor relação entre teoria e prática.

Segundo Delgado e Velez (2005), as IES passaram a introduzir a temática ambiental em seus processos de gestão a partir dos anos 1970. Atualmente existem cerca de 140 IES (a maioria na Europa) que incorporam os princípios de gestão ambiental na administração e na gestão acadêmica, sendo norteadas pelas normas ISO 14001. No Brasil, o SGA está sendo implantado em algumas universidades, como na Universidade Federal de Santa Catarina, na Universidade Católica de Brasília e na Universidade do Vale do Rio Sinos.

A Universidade Federal de Sergipe ainda não possui um efetivo SGA, apesar dos inúmeros problemas ambientais que apresenta. $\mathrm{O}$ que se tem feito nos últimos anos foram projetos de cunho ambiental nos campi, principalmente no campus Prof. José Aloísio de Campos. Dentre os projetos, o que se destaca é o Programa UFS Ambiental, que iniciou em 2010 e tem como objetivos implantar várias ações ambientais efetivas nos campi da UFS, como coleta seletiva, redução do desperdício em energia, água e alimentação, sensibilização da comunidade acadêmica para a importância de uma gestão ambiental nos campi como forma de garantir a sustentabilidade do ambiente universitário, informação da comunidade, principalmente a acadêmica, dos resultados obtidos com as ações ambientais, entre outras.

Segundo Dias (2006), todas as instituições de ensino já deveriam ter uma política ambiental definida em sua estrutura e função. O que se tem notado na esfera pública é um esforço do governo em implantar a Agenda Ambiental na Administração Pública (A3P), que visa à gestão socioambiental sustentável das atividades administrativas e operacionais do governo, como as universidades públicas, a partir da inserção dos critérios ambientais que vão desde uma mudança nos investimentos, compras e contratação de serviços pelo governo até uma gestão adequada dos resíduos gerados e dos recursos naturais utilizados (MINISTÉRIO DO MEIO AMBIENTE, 2010). O problema desse programa, criado em 1999, é que sua adesão ocorre de forma voluntária, e muitas instituições ainda não possuem a percepção da 
realidade ambiental. Isso é verificado no número de parcerias: até o ano de 2010, somente a Universidade Federal do Rio Grande do Sul havia aderido ao programa. A Universidade Federal de Santa Catarina está em andamento com o Termo de Adesão à A3P.

\section{MATERIAL E MÉTODOS}

\subsection{Caracterização do sistema de estudo}

O campus universitário Prof. José Aloísio de Campo está situado na área urbana do município de São Cristóvão, Sergipe (Fig. 1), próximo aos loteamentos Parque Universitário e Jardim Universitário (antigo Barreiro) na porção sul e ao bairro Jardim Rosa Elze na porção oeste, sendo este o mais populoso, com 2.623 habitantes (SÃO CRISTÓVÃO apud DUTRA, 2008).

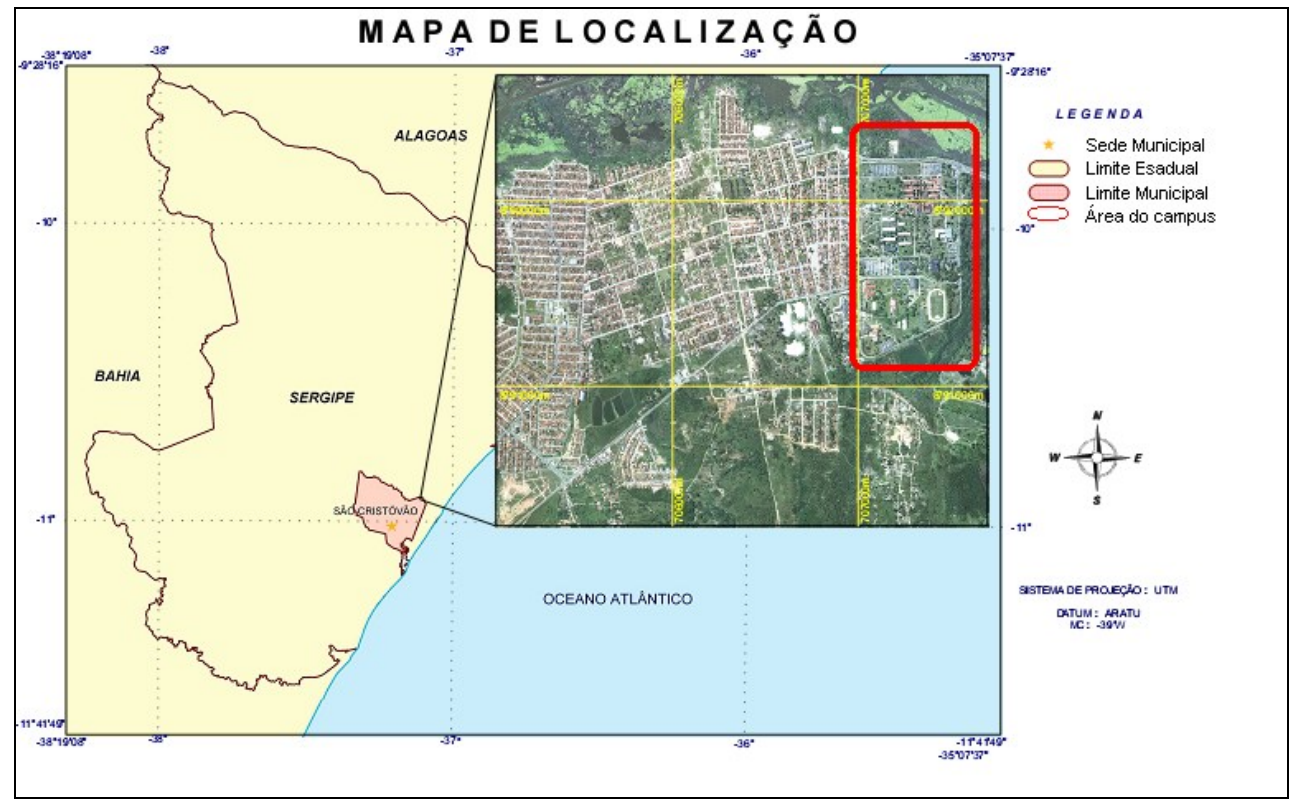

Figura 1 Mapa de localização geográfica do campus Prof. José Aloísio de Campos Fonte: Adaptado de Petrobrás (apud DUTRA, 2008).

Ao norte, o campus faz limite com a Avenida Marechal Rondon e, a oeste, com a Avenida Governador João Alves Filho e com a Avenida José Conrado de Araújo, popularmente conhecida como Avenida João Bebe Água. No entorno se encontra a Escola Estadual Armindo Guaraná, localizada na porção sudoeste do campus. Na porção noroeste, encontra-se um posto de gasolina e o Sindicato dos Trabalhadores da Universidade de Sergipe (SINTUFS). Em relação às áreas naturais, se encontra, na porção norte do campus, o rio Poxim, afluente do rio Sergipe e responsável por 30\% do abastecimento hídrico de Aracaju 
(SILVA et al., 2004). Também se encontram uma área de Mata Atlântica que margeia as porções norte e leste do campus e que está passando por um processo intenso de degradação.

Dentro do campus existe uma divisão entre as áreas construídas e as áreas naturais. As áreas construídas representam as salas de aula, centros de estudos, reitoria, biblioteca, prefeitura, restaurantes, lanchonetes, banco, escola, setor esportivo, fórum, almoxarifado, estacionamento etc. As áreas naturais representam a vegetação e a hidrografia. A vegetação é constituída, principalmente, por exemplares da Mata Atlântica. Este e outros tipos de vegetação encontram-se, em sua maioria, na porção próxima ao canal e à área de charco (Fig. 2).

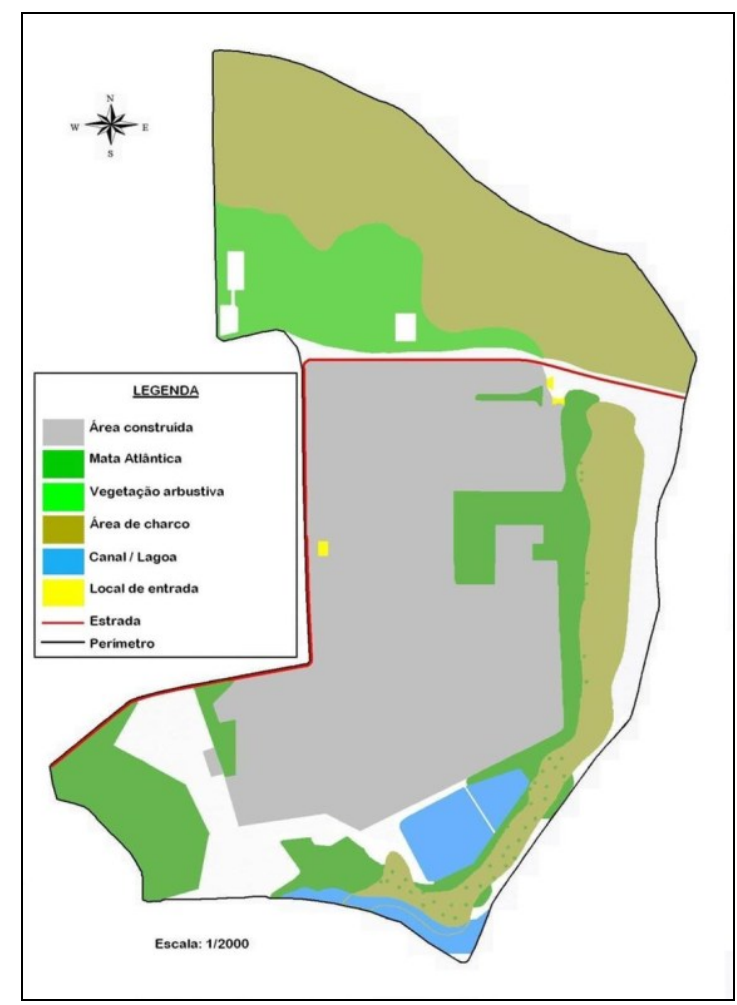

Figura 2 Divisão do campus Prof. José Aloísio de Campos Fonte: Adaptado e modificado de UFS/PREFCAMP (2008).

\subsection{Sujeitos da pesquisa}

A pesquisa foi do tipo qualitativa, com a utilização do método fenomenológico. A seleção dos sujeitos foi intencional, em função da natureza, dos objetivos da pesquisa, da disponibilidade de tempo e do tamanho dos grupos estabelecidos.

Os sujeitos da pesquisa foram escolhidos entre os diferentes grupos socioculturais de interação com o campus Prof. José Aloísio de Campos, reconhecidos a partir da investigação 
exploratória da área de estudo. São eles: a) alunos de graduação e pós-graduação; b) servidores técnico-administrativos; c) professores; d) pessoas do entorno; e) gestores.

O universo amostral da área de pesquisa é bastante elevado. Segundo o relatório estatístico da UFS para o ano de 2009, no campus Prof. José Aloísio de Campos existem 13.732 alunos de graduação, 807 professores de ensino superior com quadro permanente e 1.163 servidores técnico-administrativos com quadro efetivo (UFS, 2010b).

$\mathrm{Na}$ impossibilidade de investigar todos os sujeitos dos grupos de interação com o referido campus, foram amostrados dez indivíduos de cada grupo, exceto o grupo de gestores, composto por dois indivíduos. Desse modo, foram amostrados no total 42 indivíduos.

Sobre a quantidade de entrevistados, Moreira (2004) afirma que, no caso de uma pesquisa qualitativa que utilize o método fenomenológico, a amostra será frequentemente intencional e com poucos participantes, sendo no máximo dez, com a mediana por volta de seis a oito participantes.

A seleção dos professores e alunos de graduação aconteceu nos quatro centros de estudos existentes na UFS: Centro de Ciências Biológicas e da Saúde (CCBS), Centro de Ciências Exatas e Tecnologia (CCET), Centro de Ciências Sociais Aplicadas (CCSA) e Centro de Educação e Ciências Humanas (CECH). Foram adotados os seguintes critérios:

1) Dois professores por centro de estudo, sendo que um trabalhava na instituição por no máximo três anos e outro trabalhava na instituição por no mínimo cinco anos. No caso dos professores de pós-graduação, foram dois professores de programas diferentes, sendo um do programa de mestrado e o outro do programa de doutorado, independentemente da quantidade de anos de trabalho;

2) Dois alunos por centro de estudo. Levando-se em conta que o tempo médio de graduação por aluno é de cinco anos (UFS, 2010a), um dos alunos estudava na instituição por no máximo dois anos (ou quarto período) e o outro estudava na instituição por no mínimo três anos (ou sétimo período). No caso dos alunos de pósgraduação, foram dois alunos de programas diferentes, sendo que um estudava no programa de mestrado e o outro no programa de doutorado, independentemente da quantidade de anos de estudo (ou períodos).

Em relação aos servidores técnico-administrativos e pessoas do entorno da UFS, adotou-se um critério semelhante:

1) Cinco servidores trabalhavam na instituição por no máximo três anos e cinco servidores trabalhavam por no mínimo cinco anos; 
2) Cinco pessoas do entorno moravam na região por no máximo três anos e cinco moravam por no mínimo cinco anos.

Os dois gestores selecionados foram o reitor e o vice-reitor da Universidade Federal de Sergipe.

\subsection{Instrumentos da pesquisa}

Os instrumentos básicos para a coleta de dados foram um questionário com questões abertas e fechadas e uma entrevista não padronizada. Os questionários foram propostos para investigação das características dos sujeitos (dados pessoais, escolaridade, atividade profissional e residência), das características dos grupos (padrões de utilização do campus Prof. José Aloísio de Campos e seu entorno), de alguns aspectos do sistema de utilização pelo homem e de outras características da interação dos sujeitos com a área em questão. A entrevista não padronizada foi proposta para investigar: a) experiência dos sujeitos em relação ao campus Prof. José Aloísio de Campos; b) os processos de percepção do significado, da identidade e da estrutura (limites, pontos de entrada, elementos estruturais representativos e zonas); e c) a escolha dos usos para o campus e seu entorno.

Algumas questões da entrevista não padronizada foram associadas ao teste gráfico do mapa mental, incorporando um mapa-contorno da área do campus Prof. José Aloísio de Campos (Fig. 3).

Os mapas mentais (também chamados de mapas cognitivos) são técnicas para descobrir as imagens de relações espaciais e as características ambientais que as pessoas "trazem em suas cabeças" e as atitudes que detêm em relação a elas (WHYTE, 1977). Essa estratégia auxiliou a expressão gráfica da imagem mental dos elementos estruturais da paisagem, configurando uma facilitação operacional para a comparação das imagens mentais dos grupos.

As informações geradas pelos mapas mentais foram transferidas e processadas no editor de imagem Paint 3.4, resultando num mapa-síntese para cada grupo de interação, como proposição de convergência de localização da estrutura e escolha de usos para o campus e seu entorno. 


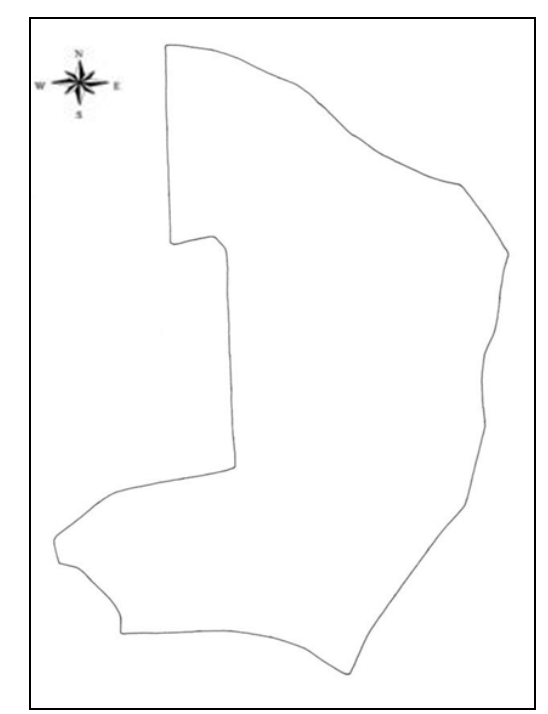

Figura 3 Mapa-contorno físico da área do campus Prof. José Aloísio de Campos, incorporado ao teste gráfico do mapa mental

Fonte: Elaborado pelos autores.

$\mathrm{Na}$ estruturação do mapa-síntese foram considerados predominantes, em termos de localização, os limites, pontos de entrada, elementos representativos, zonas e escolha de usos, que foram assinalados num mesmo local por no mínimo dois sujeitos de cada grupo de interação, exceto pelos gestores, que apresentaram somente dois mapas mentais.

O modelo de investigação do sistema de percepção para o campus Prof. José Aloísio de Campos foi proposto a partir da adaptação do modelo de Whyte (1977) (Fig. 4). Nele são descritas as variáveis de estado (características e experiência dos sujeitos e dos grupos), as variáveis de saída (escolha de usos) e os processos de percepção (percepção do significado, da identidade e da estrutura da paisagem, tais como limites, pontos de entrada, elementos representativos e classificação em zonas). Nesse processo, também foi inserida a percepção do valor afetivo.

Nesse modelo, as variáveis de estado estão numa ordem determinada pela distância entre o ponto de decisão e a interação homem-meio ambiente, bem como pelo nível em que se situa aquele que decide, que pode ir de um gerenciador individual, que toma decisões para o seu próprio interesse ou de sua família, a um gerenciador coletivo, que decide interesses de vários usuários. 


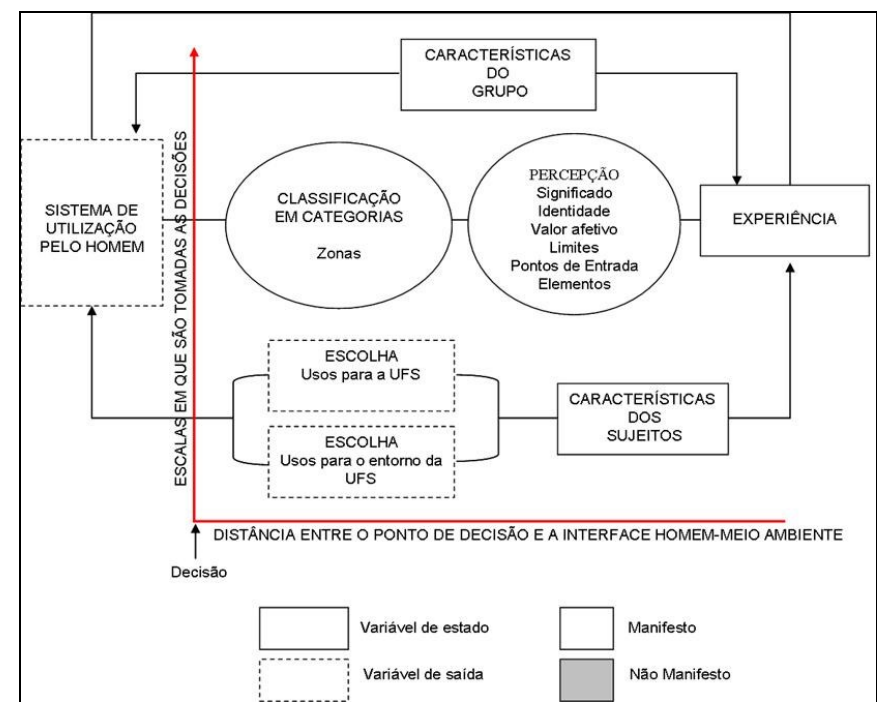

Figura 4 Modelo de investigação do sistema de percepção ambiental proposto para o campus Prof. José Aloísio de Campos Fonte: Adaptado de Whyte (1977).

O fluxo gráfico no modelo move-se da direita para a esquerda, incidindo as variáveis de estado mais diretamente sobre as variáveis de saída para uma situação específica. E, como o fluxo se move a partir da base ao topo do diagrama, as variáveis de saída se tornam mais relevantes para o coletivo, em vez da tomada de decisão individual, apesar de uma não ser exclusiva da outra. O modelo mostra uma progressão, desde as características dos indivíduos e do grupo, passando pelas variáveis de estado até as decisões e as escolhas que afetam o meio ambiente.

\section{RESULTADOS E DISCUSSÕES}

\subsection{Características dos sujeitos dos grupos}

Os sujeitos entrevistados foram quase proporcionalmente dos dois sexos, sendo vinte e dois sujeitos do sexo feminino e vinte do sexo masculino. A média de idade do grupo dos alunos foi 24,3 anos, sendo a maioria jovem, em detrimento do grupo dos gestores, com média de 53 anos. O grupo das pessoas do entorno teve média de idade de 26,3 anos, próxima à média do grupo de alunos. A média de idade dos servidores técnico-administrativos amostrados na pesquisa foi de 38,9 anos e 43 anos para os professores.

As atividades profissionais dos sujeitos variaram entre os grupos de alunos, servidores técnico-administrativos, professores, pessoas do entorno e gestores, sendo estas principalmente associadas à experiência com a Universidade Federal de Sergipe. 
Em relação à escolaridade, a maior parte dos grupos terminou o ensino fundamental e médio em vários municípios do estado de Sergipe ou em outros estados da federação. De todos os sujeitos amostrados, somente três servidores técnico-administrativos e duas pessoas do entorno não possuem graduação. Os outros sujeitos concluíram ou estão cursando a graduação, sendo muitos deles na Universidade Federal de Sergipe.

A maior parte dos sujeitos entrevistados (com exceção do grupo das pessoas do entorno) residiu ou reside atualmente em Aracaju, com o tempo de residência bastante variado. No grupo das pessoas do entorno, a maioria residiu anteriormente em outros municípios sergipanos.

Os padrões de interação dos sujeitos dos grupos de alunos, servidores técnicos administrativos, professores, pessoas do entorno e gestores com a Universidade Federal de Sergipe foram "estudo", "trabalho" e "lazer", principalmente no campus Prof. José Aloísio de Campos. Esse resultado revelou um padrão de interação já esperado, em que o estudo foi o padrão mais citado pelo grupo dos alunos e das pessoas do entorno, sendo este último grupo composto em sua maioria por alunos ou ex-alunos da UFS. O trabalho foi o padrão de interação mais citado pelos grupos que possuem suas atividades laborais na UFS, como o grupo dos servidores técnico-administrativos, professores e gestores. O padrão de interação "lazer", apesar de ser citado por todos os grupos, foi mais marcado pelo grupo das pessoas do entorno. Isso foi um reflexo da falta de opções de áreas de lazer no entorno do campus, fazendo da instituição um importante polo de lazer para a comunidade próxima.

\subsection{Experiência dos grupos de interação com a UFS}

A experiência de interação com a Universidade Federal de Sergipe a partir do primeiro contato, o período pelo qual essa interação persiste e a sua frequência variaram entre os grupos de alunos, servidores técnico-administrativos, professores, pessoas do entorno e gestores. A maioria dos alunos e das pessoas do entorno iniciou sua experiência com a UFS já adulto, quando foi fazer a inscrição para o vestibular, a matrícula no curso de graduação ou alguma pesquisa no campus. A interação de alguns servidores técnico-administrativos e dos gestores ocorreu ainda no início da fundação da instituição, no final da década de 1970 e início da década de 1980. Já em relação aos professores, a maior parte iniciou sua experiência com a universidade por meio do concurso para docente, durante as décadas de 1990 e 2000. 
A intensidade da interação com a Universidade Federal de Sergipe em termos de número e periodicidade de visitas à instituição foi homogênea entre os grupos de alunos, servidores técnico-administrativos, professores e gestores, variando um pouco entre o grupo das pessoas do entorno. Este último apresentou uma intensidade de interação semelhante aos dos outros grupos somente pelos sujeitos que estudam no campus.

Os locais e objetivos da interação variaram entre os grupos, estando diretamente relacionados aos usos que estes fazem da universidade. Os alunos frequentam locais relacionados diretamente à sua experiência com o estudo. Também se verificaram experiências com a alimentação e o lazer. Os locais mais frequentados foram as salas de aula, a biblioteca central, o restaurante universitário e a praça de convivência próximo as salas de aula. Os servidores técnico-administrativos frequentam os locais relacionados principalmente à sua lotação/posto de trabalho, como a reitoria, biblioteca central, didáticas, restaurante universitário e prefeitura. O grupo dos professores frequenta diversos locais, relacionados principalmente ao trabalho e à pesquisa. Pode-se também destacar a experiência desse grupo com o setor de serviço bancário, pois, junto com as salas de aula, a reitoria e a biblioteca central, o Banco do Brasil figura entre os locais mais citados. Para o grupo das pessoas do entorno, a frequência esteve relacionada principalmente à alimentação, ao lazer e ao estudo. Os locais mais citados pelo grupo foram o restaurante universitário, o departamento de educação física, com seu ginásio e academia de ginástica, a biblioteca central, a reitoria e as salas de aula. Já para os gestores, a interação com a Universidade Federal de Sergipe foi voltada para o estudo e trabalho, com a frequência em diversos locais nos cinco campi.

\subsection{Caracterização perceptiva do sistema de estudo}

A caracterização perceptiva dos grupos de alunos, servidores técnico-administrativos, professores, pessoas do entorno e gestores em relação à atribuição de significado, identidade, valor afetivo, estrutura, escolha de usos para o campus Prof. José Aloísio de Campos e seu entorno foram obtidas através do tratamento, análise, descrição e interpretação dos dados de respostas às questões da entrevista e aos mapas-síntese.

\section{- Significado}

Para todos os grupos estudados, o significado mais importante da Universidade Federal de Sergipe foi o estudo. Isso se caracterizou pela percepção da UFS como um local 
público onde se pode adquirir conhecimento e experiência para uma formação profissional e pessoal. Por ser um local de transformação e transição para a fase adulta, a instituição se torna uma importante referência para a vida dos sujeitos.

O significado "trabalho" foi relacionado, no grupo dos alunos, dos servidores técnicoadministrativos e dos professores, à formação profissional, assim como o significado "estudo", tendo sido relacionado também ao lócus de trabalho e ao sustento para os grupos com atividades laborais na instituição, como servidores e professores. O significado "trabalho" teve uma conotação bastante positiva, revelada pela satisfação dos sujeitos em trabalhar na instituição e pela vontade futura de outros sujeitos em fazer parte do quadro efetivo da instituição.

O significado "amizade" ofereceu um entendimento de que a instituição não é só um local de estudo e trabalho, como afirmado pelo grupo dos alunos, funcionários e pessoas do entorno, mas também um local relevante de convívio social e de construção de laços afetivos.

O lazer foi mencionado pelo grupo das pessoas do entorno, que usufruem do espaço físico da instituição para praticar esportes e fazer academia de ginástica, bem como para frequentar festas.

\section{- Identidade}

A identidade da Universidade Federal de Sergipe mais reconhecida por todos os grupos foi "área de estudo", obtendo-se uma percepção similar com o significado "estudo".

A estrutura do campus também foi bastante reconhecida pelos grupos (com exceção dos gestores). Ela esteve relacionada aos aspectos físicos, espaciais, estéticos, organizacionais e ambientais do campus. A maioria dos sujeitos percebeu a estrutura do campus como negativa.

Outra identidade reconhecida foi "área em fase de crescimento", percebida pelo grupo dos servidores técnico-administrativos e professores. Para a maioria destes, a expansão da UFS é benéfica no que se refere à melhora do ensino, da estrutura física e das relações sociais e profissionais.

A área verde foi reconhecida pelo grupo dos alunos, servidores técnicoadministrativos e professores. Esses grupos mostraram-se preocupados com os impactos presentes e futuros da área verde do campus. Ao relatarem suas angústias, estavam cientes de 
que, para a resolução dos problemas ambientais do campus, é preciso um plano de ação que interligue gestão e educação ambiental.

A área de convivência foi reconhecida por alunos, professores e gestores. Essa identidade se apresentou importante para os sujeitos, por envolver um amadurecimento das relações sociais e a oportunidade de conviver com a diversidade.

A última identidade reconhecida foi o prazer, indicada pelo grupo dos gestores como ligação afetiva.

\section{- Valor afetivo}

$\mathrm{Na}$ análise das entrevistas foram encontradas nove categorias sobre o valor afetivo positivo sobre a UFS. São elas: estudo, trabalho, vegetação, relação profissional, relação social, estrutura (física, material e funcional), esporte, ambiente e comportamento.

Em relação ao valor afetivo negativo sobre a UFS, também foram encontradas nove categorias semelhantes: estudo, administração, vegetação, relação profissional, relação social, estrutura (física, material e funcional), esporte, ambiente e comportamento.

No que se refere à representação, o grupo dos alunos valoriza mais o estudo; o grupo dos professores valoriza mais o trabalho; o grupo dos servidores técnico-administrativos valoriza mais o estudo e o trabalho; já os grupos das pessoas do entorno e dos gestores valorizam mais as relações sociais.

\subsubsection{Estrutura do campus Prof. José Aloísio de Campos}

Na percepção dos componentes da estrutura (limites, pontos de entrada, elementos representativos e zonas) foram identificados landmarks, ou seja, marcos da paisagem que foram percebidos pelos grupos. Esses marcos foram representados espacialmente nos mapassíntese e refletem como os grupos percebem a estrutura do campus a partir de suas vivências, retratos da imaginação e expectativas.

\section{- Limites (Fig. 5)}

O único limite do campus indicado por todos os grupos foram as vias expressas que margeiam o campus. Esse landmark se torna expressivo por ser um elemento de primeiro contato. 
Os limites "terminal de ônibus", "vegetação" e "hidrografia" foram indicados pelo grupo dos alunos, servidores técnico-administrativos, professores e pessoas do entorno, por fazerem parte da paisagem nos pontos de entrada do campus. No que se refere à vegetação, poucos sujeitos foram capazes de identificar o seu estado de conservação, devido a não saberem de quem é a responsabilidade pela conservação da área e qual a função ecológica que esta exerce no ambiente.

O limite "bairro Rosa Elze" foi indicado por três grupos: alunos, servidores técnicoadministrativos e professores. Um fato curioso foi a não percepção do bairro pelos moradores, representados pelas pessoas do entorno. Esses sujeitos perceberam o bairro fragmentado, representado somente por suas residências e locais de interesse.

O limite "posto de gasolina" foi indicado pelos grupos dos servidores técnicoadministrativos, professores e pessoas do entorno, e esteve relacionado ao trajeto realizado pelos grupos para chegarem ao campus.

As residências foram indicadas pelos grupos dos alunos e das pessoas do entorno. Sua percepção como limite está relacionada à proximidade com o comércio do entorno do campus e com as próprias residências de alguns sujeitos.

Os limites "brejo" e "sindicato (SINTUFS)" foram indicados por um só grupo: pessoas do entorno. O brejo foi indicado devido à percepção do rio, que, na cheia, alaga a área de vegetação rasteira; o sindicato, pelo maior contato visual dos sujeitos, uma vez que ele está situado próximo ao campus e ao comércio.

O loteamento Barreiro teve sua indicação como limite pelo grupo dos servidores técnico-administrativos e se baseou no contato destes com os bairros próximos ao campus.

O limite "rotatória" foi indicado somente pelo grupo dos alunos e esteve ligado principalmente ao percurso obrigatório feito pelo transporte público para chegar ao terminal de ônibus.

A escola indicada como "Armindo Guaraná" foi percebida pelo grupo dos professores e se fundamentou na interação desses sujeitos com a escola através de projetos pedagógicos. 


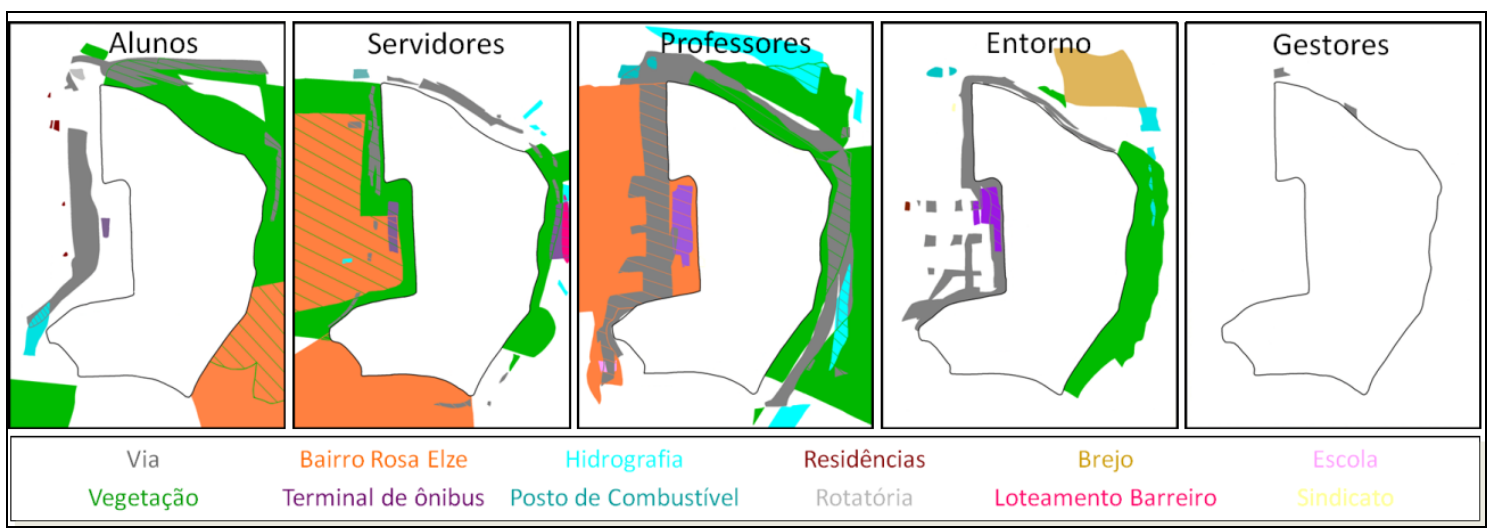

Figura 5 Mapa-síntese dos limites do campus Prof. José Aloísio de Campos pelos grupos de interação Fonte: Elaborado pelos autores.

\section{- Pontos de entrada (Fig. 6)}

O ponto de entrada do campus mais apontado por todos os grupos, com exceção dos gestores, foi o localizado na região centro-oeste, próxima ao terminal de ônibus. Os gestores identificaram como ponto de entrada a região norte, próxima à Avenida Marechal Rondon, onde há uma entrada para carros.

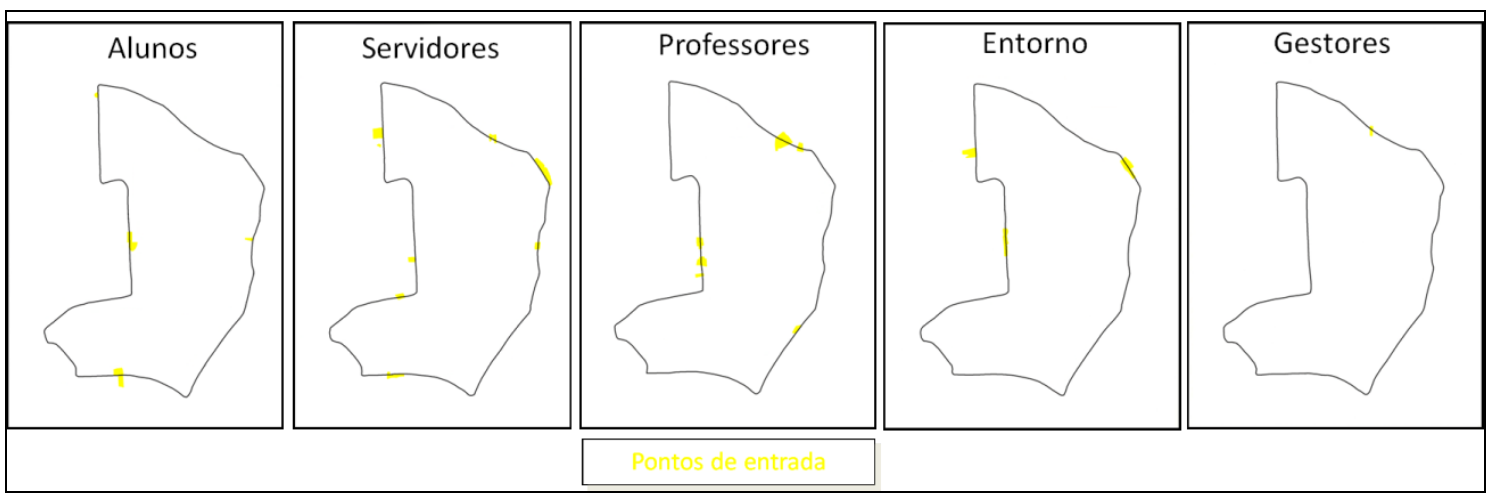

Figura 6 Mapa-síntese dos pontos de entrada do campus Prof. José Aloísio de Campos pelos grupos de interação

Fonte: Elaborado pelos autores.

\section{- Elementos representativos (Fig. 7)}

Todos os grupos evidenciaram as salas de aula como os elementos mais representativos do campus. Para os grupos, isso se caracterizou pelo fato de nesses prédios ocorrer a maior parte do processo de ensino e aprendizagem, e por serem as edificações mais destacadas na paisagem do campus. 
Para o grupo dos alunos, servidores técnico-administrativos, professores e pessoas do entorno, outro elemento representativo evidenciado foram os centros de estudos, onde são realizadas as pesquisas.

O elemento representativo "biblioteca central" foi o terceiro elemento mais evidenciado pelo grupo dos alunos, servidores técnico-administrativos e pessoas do entorno. Esses grupos percebem a biblioteca central por possuírem uma experiência acadêmica com a UFS. Desse modo, a biblioteca torna-se um importante espaço de estudo.

A reitoria foi considerada um elemento importante para os grupos dos servidores técnico-administrativos, professores e pessoas do entorno, devido à sua função de administração e gestão da universidade.

A prefeitura foi o elemento representativo evidenciado pelo grupo dos técnicoadministrativos e professores, estando essa percepção relacionada ao posto de trabalho ou à aquisição de recursos.

O restaurante universitário foi o elemento evidenciado pelo grupo dos servidores técnico-administrativo e das pessoas do entorno, e sua importância esteve relacionada à alimentação acessível e ao espaço de interação.

O departamento de Educação Física foi evidenciado como elemento representativo somente pelo grupo dos servidores técnico-administrativos. Esse grupo citou vários setores, como estádio, quadra de esportes, piscina e campo de futebol. Porém, o mais lembrado foi o campo de futebol, por ser um dos mais frequentados.

A via interna do campus esteve caracterizada pelo local de trânsito das pessoas dentro do campus e foi evidenciada somente pelo grupo dos professores.

A vegetação, a guarita e o Banco do Brasil foram evidenciados por um só grupo: o das pessoas do entorno. A vegetação foi relacionada à presença de áreas verdes em diversos locais no campus. A guarita foi associada ao ponto de entrada do campus. O Banco do Brasil foi indicado como elemento devido à sua importância e ao fácil acesso para as transações bancárias, já que não existe outra agência bancária próxima. 


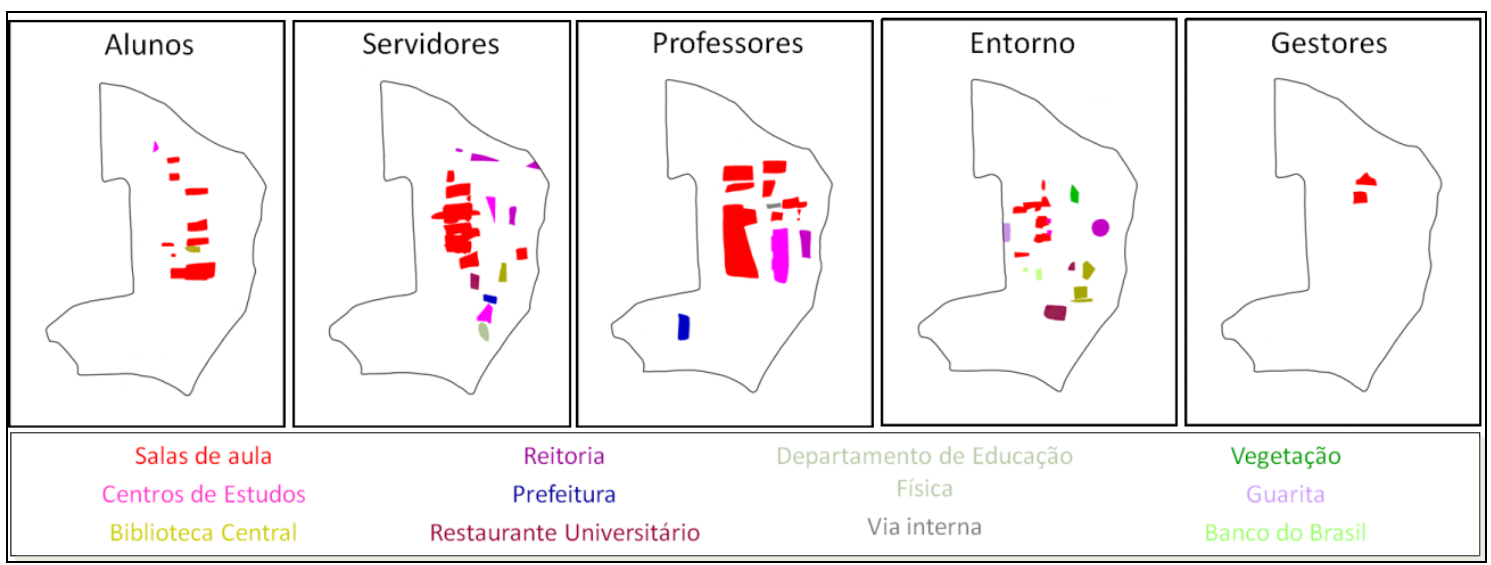

Figura 7 Mapa-síntese dos elementos representativos do campus Prof. José Aloísio de Campos pelos grupos de interação

Fonte: Elaborado pelos autores.

\section{- Zonas (Fig. 8)}

Em relação ao critério "pesquisa", todos os grupos perceberam a zona "centros de estudos" como a mais importante do campus. A biblioteca central foi percebida pelo grupo dos alunos e servidores técnico-administrativos. A pós-graduação e o Núcleo de Petróleo e Gás foram percebidos como zonas somente pelo grupo das pessoas do entorno. Essa percepção esteve relacionada à construção recente no campus da área de vivência e lazer.

No que se refere ao critério "aulas", a zona salas de aula foi percebida por quase todos os grupos (com exceção dos gestores), e se caracterizou pela função pedagógica.

A administração foi o critério para as zonas "prefeitura" e "reitoria", sendo estas percebidas por quase todos os grupos, com exceção dos gestores. A zona "prefeitura" foi relacionada principalmente à infraestrutura da universidade.

A zona "restaurante universitário", incorporada ao critério "convivência", foi percebida como zona somente pelo grupo dos servidores técnico-administrativos. Para esse grupo, essa zona ultrapassou o objetivo de alimentação, tornando-se um local de integração e convivência dos grupos.

No que tange ao critério "lazer", foram percebidas as zonas "departamento de Educação Física" e "vegetação". A primeira foi percebida pelo grupo dos servidores técnicoadministrativos e professores, e esteve relacionada principalmente ao campo de futebol. A segunda foi percebida pelo grupo dos alunos e esteve fortemente ligada à praça central arborizada, às áreas verdes entre os centros de estudos e as salas de aula e à vegetação de Mata Atlântica. 


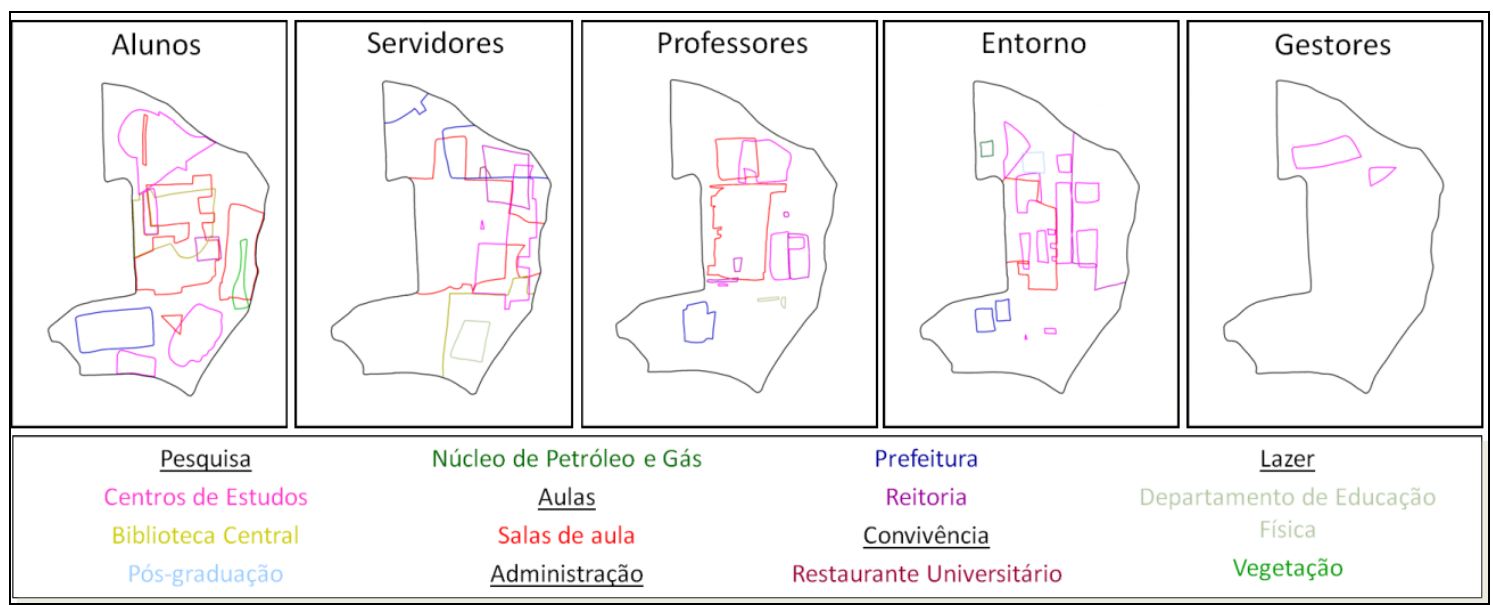

Figura 8 Mapa-síntese das zonas do campus Prof. José Aloísio de Campos pelos grupos de interação Fonte: Elaborado pelos autores.

\subsubsection{Escolha de usos para o campus Prof. José Aloísio de Campos e seu entorno}

Na percepção da escolha de usos para o campus e seu entorno, foram identificados os landmarks nos mapas-síntese, mostrando como os grupos idealizam o campus e o seu entorno, a partir de suas vivências, retratos da imaginação e expectativas. O grupo dos gestores não convergiu no mapa-síntese nenhuma escolha para o campus e seu entorno. $\mathrm{O}$ grupo das pessoas do entorno não convergiu nenhuma escolha para o entorno do campus.

\section{- Escolha de usos para o campus (Fig. 9)}

Todos os grupos indicaram a necessidade da estruturação das áreas existentes no campus, principalmente os centros de estudos. Essa estruturação esteve mais relacionada ao interesse individual do que ao do grupo, a fim de garantir maior conforto e comodidade para seu trabalho e estudo.

As salas de aula e a biblioteca central foram indicadas para estruturação pelos grupos dos alunos, servidores técnico-administrativos e pessoas do entorno com o objetivo de melhorar as condições de estudo e aproveitamento do espaço.

A reitoria foi indicada para estruturação pelos grupos dos professores e pessoas do entorno, estando relacionada à melhora do acesso ao público.

O restaurante universitário foi indicado para estruturação somente pelo grupo dos alunos, com a sugestão de ampliar seu espaço e melhorar a alimentação servida. Além disso, esse grupo sugeriu a introdução da coleta seletiva de lixo, sendo essa ação já incorporada pelo projeto vigente "UFS Ambiental". 
A prefeitura e as vias do campus foram indicadas para estruturação somente pelo grupo dos servidores técnico-administrativos. Para o grupo, a prefeitura deveria ser mais organizada por se tratar de uma parte administrativa. Já as vias deveriam ser mais bem sinalizadas e poderiam incorporar uma via de transporte coletivo dentro do campus.

Por fim, o departamento de Educação Física foi percebido como área a ser estruturada pelo grupo das pessoas do entorno. O grupo sugeriu o aumento e revitalização do complexo esportivo, por ser uma área de lazer muito importante para o grupo.

No que tange à conservação e preservação, somente o grupo dos servidores técnicoadministrativos e professores escolheram essa ação para o campus, destacando a necessidade de arborização para finalidade ecológica, estética e pedagógica e construção de uma horta. $\mathrm{Na}$ horta seriam cultivados legumes e verduras para o restaurante universitário ou para a comunidade. O plantio utilizaria o adubo proveniente da compostagem dos resíduos orgânicos gerados no próprio restaurante universitário, estimulando, desse modo, a consciência ambiental.

Também foi identificada a construção de uma residência universitária pelo grupo das pessoas do entorno, o que beneficiaria muitos sujeitos desse grupo que são de outros municípios e moram de aluguel para estarem próximos ao seu local de estudo.

A adequação das vias para a prática de caminhada e ciclismo foi sugerida como escolha de uso pelo grupo dos professores, como forma de lazer.

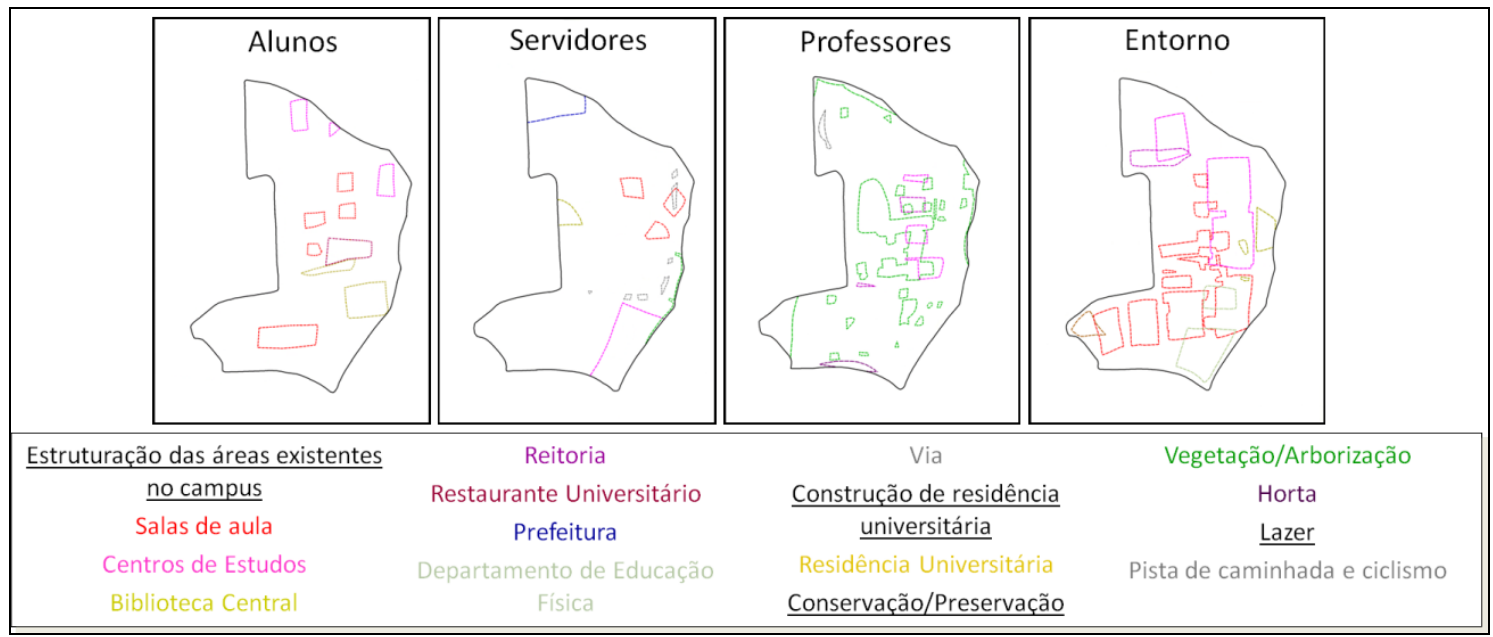

Figura 9 Mapa-síntese da escolha de usos para o campus Prof. José Aloísio de Campos pelos grupos de interação

Fonte: Elaborado pelos autores. 


\section{- $\quad$ Escolha de usos para o entorno do campus (Fig. 10)}

Todos os grupos destacaram como escolha de usos para o campus a estruturação viária do bairro Rosa Elze, com a melhora na sinalização e infraestrutura, e a preservação e conservação da vegetação do entorno, com a arborização de praças e avenidas do bairro Rosa Elze e a utilização da área verde próximo da Avenida Marechal Rondon para pesquisa.

A preservação e conservação da hidrografia foram mencionadas como escolha de uso somente pelo grupo dos servidores técnico-administrativos e professores. Esses sujeitos destacaram a necessidade de programas de educação ambiental para sensibilizar a comunidade do entorno a respeito da poluição do rio.

Outro uso proposto pelo grupo dos alunos e professores foi a habitação, representada pelas residências. Estas poderiam ser verticalizadas, poupando espaço e atendendo a mais pessoas.

O grupo dos servidores técnico-administrativos foi o único grupo a indicar educação e segurança, a partir da construção de escolas e guaritas, como escolha de usos para o entorno. Essa percepção esteve relacionada à maior experiência e interação desse grupo com o entorno do campus, percebendo, desse modo, as necessidades da comunidade.

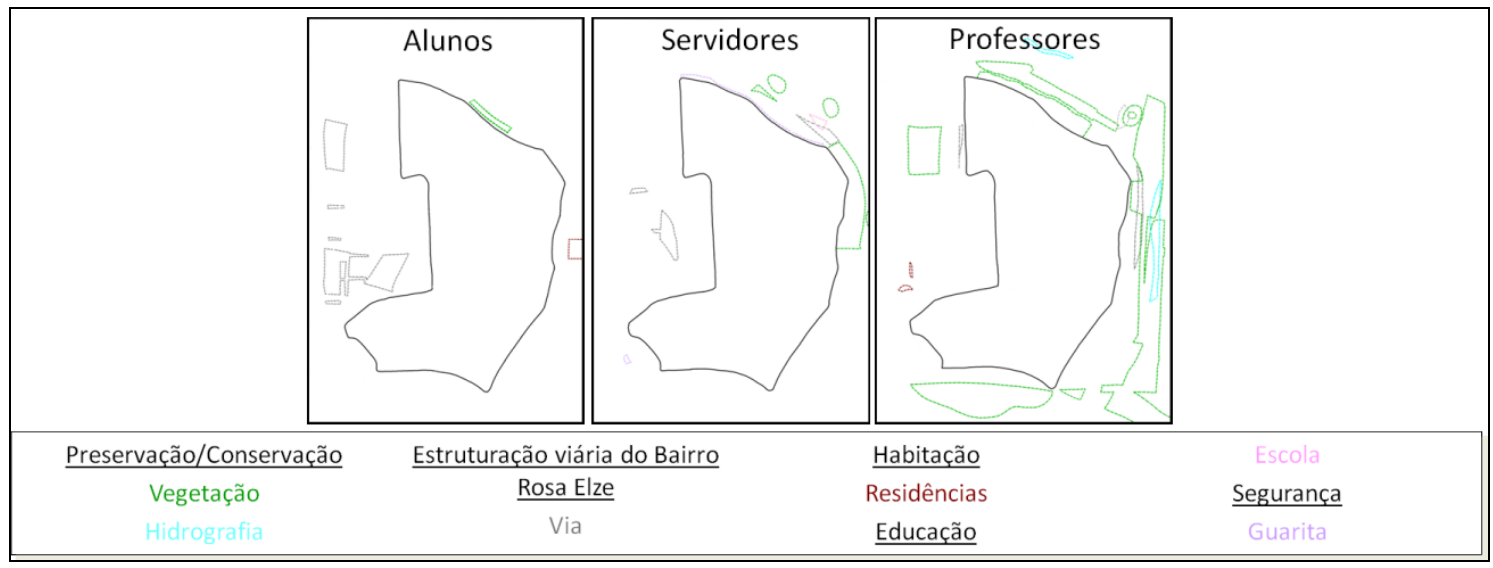

Figura 10 Mapa-síntese da escolha de usos para o entorno do campus Prof. José Aloísio de Campos pelos grupos de interação

Fonte: Elaborado pelos autores.

\subsection{Imagem perceptiva}

Com a análise das respostas dos sujeitos dos grupos à entrevista foram reveladas novas variáveis e processos não previstos no modelo de investigação inicial do sistema de percepção 
ambiental para o campus Prof. José Aloísio de Campos (Fig. 4), alguns dos quais previstos no modelo do sistema de percepção de Whyte (1977).

As variáveis, denominadas aqui emergentes, encontradas pelos grupos foram:

a) variáveis de estado - topofilia (ligação afetiva das pessoas com o meio ambiente), identidade dos sujeitos (apego ou sentimento de pertencimento de uma pessoa a um grupo ou região), egocentrismo (forma de as pessoas se referirem a si mesmas na percepção de mundo), etnocentrismo (percepção do mundo centralizada na cultura do indivíduo) e sistema de valores (conjunto de valores que fornecem um modelo normativo de comportamento para o grupo);

b) variáveis de saída - comportamento (ação realizada em resposta ao processo de escolha individual), escolha de cuidados (seleção de possibilidades de cuidados a serem empregados ao sistema de estudo) e escolha da responsabilidade de cuidar (preferência dos sujeitos na atribuição de responsabilidades ao sistema de estudo).

Os processos emergentes foram atitudes (expressão de opiniões, crenças e sentimentos que influenciam de forma positiva ou negativa a resposta do sujeito) e percepção de impactos (expressões de reconhecimento de alterações estruturais e funcionais ocorridas no sistema de estudo).

A partir da análise, descrição e discussão dos resultados, pode-se reelaborar o modelo do sistema de percepção (imagem perceptiva) para o campus Prof. José Aloísio de Campos e seu entorno (Fig. 11). Esse modelo foi reelaborado separadamente para cada grupo de interação, levando em conta as variáveis e processos previstos e os emergentes.

As imagens perceptivas dos grupos de interação foram pouco distintas, estando convergentes na manifestação da experiência e da estrutura do sistema de estudo. A escolha de usos foi divergente na manifestação para o grupo dos gestores, que não convergiu nenhuma escolha de usos para o campus e seu entorno no mapa-síntese, e para o grupo das pessoas do entorno, que não convergiu nenhuma escolha de uso para o entorno no mapa-síntese.

Em relação às novas variáveis e processos, houve uma divergência na manifestação, estando a variável de entrada "egocentrismo" não manifestada no grupo das pessoas do entorno e dos gestores, a variável de saída "escolha da responsabilidade de cuidar" não manifestada no grupo dos alunos e dos servidores técnico-administrativos e o processo emergente "atitudes" não manifestado no grupo dos professores. 


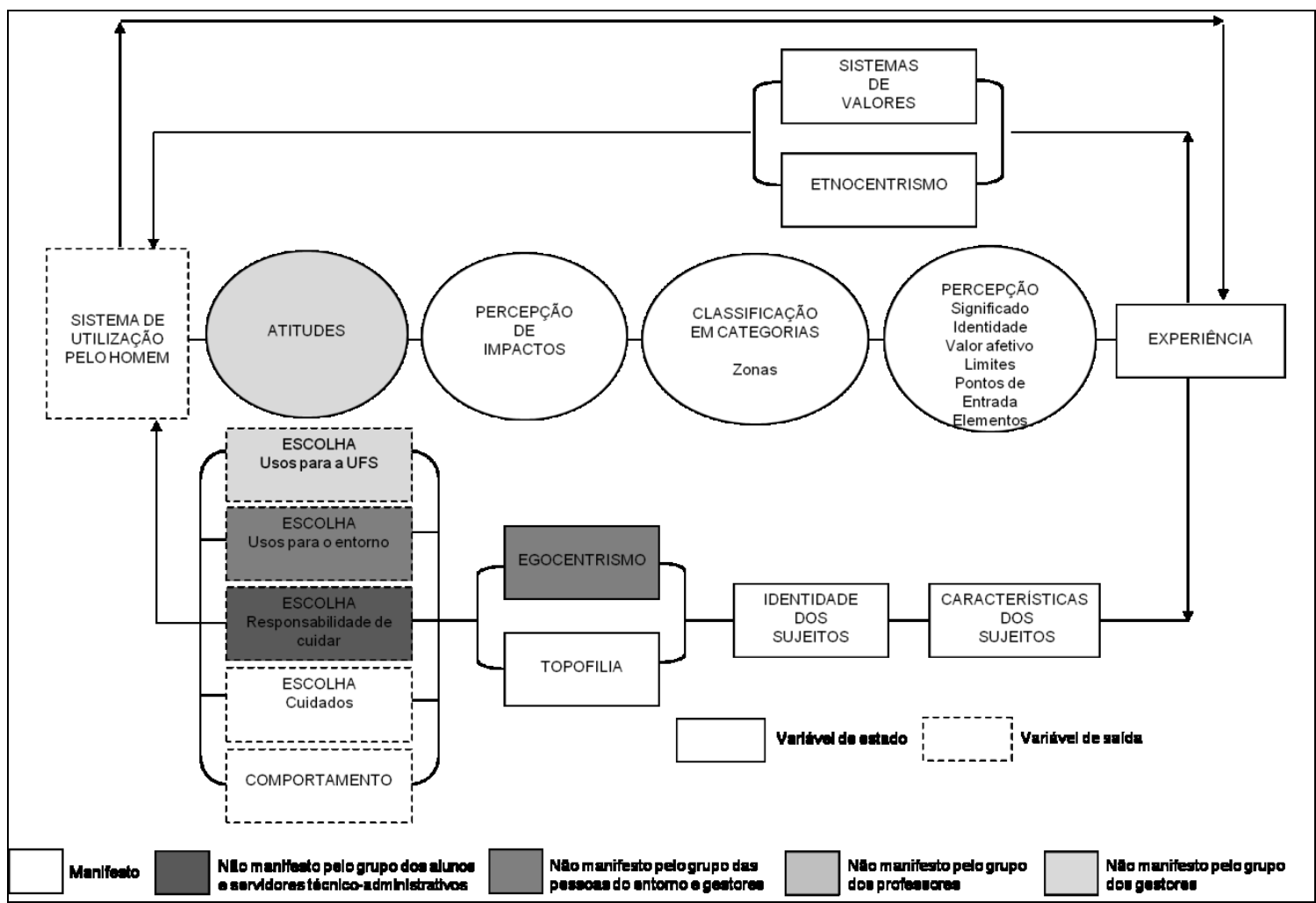

Figura 11 Imagem perceptiva do campus Prof. José Aloísio de Campos e seu entorno pelos grupos de interação

Fonte: Adaptado de Whyte (1977).

\section{CONSIDERAÇÕES FINAIS}

Os grupos dos alunos, servidores técnico-administrativos, professores, pessoas do entorno e gestores percebem diferentemente o campus Prof. José Aloísio de Campos da Universidade Federal de Sergipe, em relação à percepção de seu significado, identidade, valor afetivo, estrutura e escolha de usos, formando mapas e imagens perceptivas distintas, mediadas pelos seus padrões de interação, sistema de utilização, sistemas de valores e contexto socioeconômico-cultural.

O método de pesquisa utilizado mostrou-se adequado ao alcance do objetivo proposto, pois possibilitou a investigação da percepção ambiental do campus universitário como uma tomada de consciência além da apreensão sensorial, o que possibilitou a expressão de ideias, opiniões e atitudes dos sujeitos investigados, provocando um "despertar" de consciência sobre as questões relativas a tal área.

Os desejos essenciais de todos os grupos de interação foram principalmente estudo e trabalho, seguido por lazer pelo grupo das pessoas do entorno. Esse desejo foi manifestado 
pela intersecção de atitudes, comportamentos, expressões e opiniões referentes aos padrões e objetivos de interação e ao significado atribuído à universidade.

A experiência dos grupos com a Universidade Federal de Sergipe foi predominantemente alta, sendo as salas de aula os locais mais frequentados por todos os grupos. As identidades estiveram relacionadas, em sua maioria, à estruturação do campus, com a descrição dos aspectos físico, espacial, estético, organizacional e ambiental, a percepção do campus como uma área de estudo propícia à aprendizagem e ao crescimento profissional e pessoal e a preocupação com os impactos ambientais na área verde. O valor afetivo atribuído à UFS foi positivo para todos os grupos no que se refere à relação social existente no campus, e negativo para a maioria quanto se tratava de estrutura, administração e ambiente do campus.

A utilização dos mapas mentais permitiu identificar os landmarks do espaço e da paisagem na estrutura e na escolha de usos dos grupos para o campus Prof. José Aloísio de Campos e seu entorno, sendo possível posteriormente a comparação da percepção imediata dos grupos. A análise revelou que todos os grupos de interação percebem mais marcadamente as áreas construídas do campus, no que diz respeito aos seus limites, seus elementos representativos e suas zonas. As áreas naturais são manifestadas principalmente pelos limites do campus, com a vegetação e a hidrografia percebidas pelos grupos dos alunos, servidores técnico-administrativos, professores e pessoas do entorno. O grupo das pessoas do entorno foi o único grupo que evidenciou a vegetação como elemento representativo, e o grupo dos alunos foi o único grupo que representou a vegetação como uma das zonas do campus.

Ao identificar a escolha de usos para o campus Prof. José Aloísio de Campos e o seu entorno, dois grupos com experiência no campus (servidores técnico-administrativos e professores) sugeriram que o campus e seu entorno são um espaço físico a ser estruturado e um espaço natural a ser conservado e preservado. O grupo dos alunos recomenda que o campus e seu entorno sejam um espaço físico a ser estruturado e somente o entorno um espaço natural a ser preservado e conservado. O grupo das pessoas do entorno indica o uso do campus como um espaço físico a ser estruturado.

As imagens perceptivas dos grupos de interação em relação às variáveis e aos processos do sistema de percepção foram pouco distintas, com os grupos possuindo um grande laço afetivo com o campus e o seu entorno (topofilia), resultando na percepção dos impactos do sistema de estudo e numa posterior escolha de cuidados para esse sistema. 
Os resultados obtidos pela investigação perceptiva do campus da Universidade Federal de Sergipe são uma importante fonte de pesquisa sobre percepção ambiental, servindo como subsídio para a discussão de projetos existentes e elaboração de novos projetos sobre gestão e planejamento do espaço universitário, a fim de garantir seu desenvolvimento e expansão de forma sustentável e de alguma forma respeitando a percepção dos grupos interatuantes desse espaço.

A Universidade Federal de Sergipe, a partir da criação do Programa UFS Ambiental, caminha para uma discussão já realizada em outros campi universitários no Brasil e no resto mundo. Cabe destacar que tais demandas serão necessárias para uma universidade que vem crescendo e se expandindo para outros campi pelo interior do estado. Desse modo, esse programa tem como desafio, conciliar o crescimento atual e futuro da instituição com a conservação de seus ambientes naturais.

No Brasil e no mundo essa conciliação entre crescimento e conservação já pode ser visualizada em universidades que implantaram um sistema de gestão ambiental com critérios compatíveis com as normas ISO 14001 (TAUCHEN; BRANDLI, 2006). Esse modelo de gestão ocorre com a integração entre planejamento, gerenciamento e política ambiental, além da democratização dos processos de tomada de decisão, com a participação de todos os grupos interatuantes. Com isso, para o alcance da gestão ambiental compartilhada, as universidades, como a Universidade Federal de Sergipe, devem conhecer primeiramente as percepções dos grupos interatuantes em seu espaço.

Os mapas mentais e as imagens perceptivas dos grupos de interação foram elaborados num tempo presente. Isso implica que alterações no campus, tanto na paisagem como nos padrões de interação, determinarão investigações futuras. Desse modo, mostra-se importante um monitoramento contínuo do sistema de percepção do campus Prof. José Aloísio de Campos e do seu entorno, bem como a investigação do sistema de percepção ambiental dos outros campi da Universidade Federal de Sergipe, como forma de garantir a gestão ambiental unificada da instituição.

\section{AGRADECIMENTOS}

À Fundação de Amparo à Pesquisa e à Inovação Tecnológica do Estado de Sergipe (FAPITEC), pelo apoio financeiro para a conclusão desta pesquisa. 


\section{REFERÊNCIAS}

ALMEIDA, J. R. de; BASTOS, A. C. S.; SILVA, D. M.; MALHEIROS, T. M. Política e planejamento ambiental. 3. ed. rev. e atual. Rio de Janeiro: Thex, 2006. 457 p.

CUNHA, L. H.; COELHO, M. C. N. Política e gestão ambiental. In: CUNHA, S. B da; GUERRA, A. J. T. (Orgs.). A questão ambiental: diferentes abordagens. 4. ed. Rio de Janeiro: Bertrand Brasil, 2008. p. 43-79.

DEL RIO. V. Cidades da mente, cidade real: percepção e revitalização da área portuária do RJ. In: DEL RIO, V.; OLIVEIRA, L. de (Orgs.). Percepção ambiental: a experiência brasileira. São Paulo: Studio Nobel; São Carlos, SP: Universidade Federal de São Carlos, 1996. p. 3-22.

DELGADO, C. C. J.; VÉLEZ, C. Q. Sistema de gestión ambiental universitária: caso politécnico Gran Colombiano, 2005. Disponível em:

$<$ http://ecnam.udistrital.edu.co/pdf/r/edge02/node03.pdf $>$. Acesso em: 25 abr. 2010.

DIAS, G. F. Educação e gestão ambiental. São Paulo: Gaia, 2006. 118 p.

DUTRA, D. R. A elaboração da Agenda 21 comunitária do bairro Rosa Elze, São

Cristóvão, Sergipe: um instrumento de participação popular. 2008. $121 \mathrm{f}$. Dissertação

(Mestrado em Desenvolvimento e Meio Ambiente). Universidade Federal de Sergipe, São Cristóvão, 2008.

FERNANDES, R. S.; VIEGAS, R.; GUANANDY, J. V. Avaliação do perfil de cidadania ambiental de estudantes do ensino médio-técnico do CEFET-RJ. Revista eletrônica do Mestrado em Educação Ambiental, v. 17, p. 195-213, jul.-dez. 2006.

JESUS, T. P. de. Caracterização perceptiva da Estação Ecológica de Jataí (Luiz Antônio, SP) por diferentes grupos sócio-culturais de interação. São Carlos, 1993, 336 p.

Dissertação (Doutorado em Ecologia e Recursos Naturais) - Centro de Ciências Biológicas e da Saúde, Universidade Federal de São Carlos.

MINISTÉRIO DO MEIO AMBIENTE. Agenda Ambiental na Administração Pública. Disponível em:

$<$ http://www.mma.gov.br/sitio/index.php?ido=conteudo.monta\&idEstrutura=36>. Acesso em: 28 abr. 2010.

MOREIRA, D. A. O método fenomenológico na pesquisa. São Paulo: Pioneira Thomson, 2004. $152 \mathrm{p}$.

SANTOS, R. F. dos. Planejamento ambiental: teoria e prática. São Paulo: Oficina de textos, 2004. 184 p.

SANTOS, J. E. dos S.; ZANIN, E. M.; OLIVEIRA, C. H.; MOSCHINI, L. E. Caracterização perceptiva do campus da UFSCar por diferentes grupos socioculturais de interação. Revista Educação Pública, Cuiabá, v. 13, n. 23, p. 11-30, jan.-jun. 2004. 
SILVA, A. de S.; BUSHINELLI, C. C. de A.; RODRIGUES, I. A.; MACHADO, R. E. Índice de sustentabilidade ambiental do uso da água: municípios da região do entorno do rio Poxim/SE. Boletim de Pesquisa e Desenvolvimento, Jaguariúna, SP, jun. 2004.

TAUCHEN, J.; BRANDLI, L. L. A gestão ambiental em instituições de ensino superior: modelo para implantação em campus universitário. Rev. Gestão \& Produção, v. 13, n. 3, p. 503-515, set.-dez. 2006.

UNESCO. Final report of the expert panel on project 13: perception of environmental quality. Paris: UNESCO, 1973. 25 p. (Series of reports of MAB).

UNIVERSIDADE FEDERAL DE SERGIPE. Prefeitura do campus "Prof. José Aloísio de Campos" (PREFCAMP). Levantamento topográfico planimétrico cadastral da área do campus universitário. São Cristóvão: UFS, jun. 2008. Escala: 1:2000.

Relatório de gestão 2009. São Cristóvão: COAVI/COGEPLAN, 2010a. 180 p.

UFS em números 2009. São Cristóvão, SE: UFS, 2010b. Folder.

WHYTE, A. V. T. Guidelines for field studies in environmental perception. Paris: UNESCO, 1977. 118 p. (MAB Technical Notes 5).

ZUBE, E. H.; SELL, J. L; TAYLOR, J. G. Landscape perception: research, application and theory. Landscape Planning, n. 9, p. 1-33, 1982. 